\title{
Isolamento e seleção de microrganismos produtores de lipase e otimização da produção enzimática
}

Isolation and selection of lipase producer microrganisms and enzymatic production optimization

\author{
J. V. M. L. Garrido*; D. F. Bispo; C. F. Silva \\ ${ }^{1}$ Departamento de Engenharia Química, Universidade Federal de Sergipe, CEP 49100-000, São Cristóvão-SERGIPE, \\ Brasil
}

*garridovictor@outlook.com

(Recebido em 25 de julho de 2017; aceito em 24 de maio de 2018)

\begin{abstract}
Lipases são enzimas de grande interesse comercial, pois são versáteis e atuam em vários ramos da indústria química, destacando as indústrias têxtil, alimentícia e de detergentes. As lipases também representam uma forma de tornar a produção industrial mais limpa, com atuações na obtenção de biodiesel ou tratamento de efluentes gordurosos. Dentre as diferentes vias de obtenção de enzimas lipolíticas, a via microbiana é a forma mais utilizada industrialmente. Tendo em vista a importância industrial da enzima, o presente trabalho teve como objetivo o isolamento e seleção de microrganismos produtores de lipases, bem como a otimização de sua produção através de fermentação submersa. Foram isoladas 12 cepas selvagens, dentre as quais três delas apresentaram destaque em análise qualitativa de produção de lipases. Uma dessas cepas foi selecionada para a realização de ensaios com base em um Delineamento Composto Central Rotacional (DCCR) $2^{3}$ a fim de otimizar sua atividade enzimática. As variáveis analisadas no DCCR foram concentração de extrato de levedura, concentração de óleo de soja e porcentagem de farelo de soja $(\mathrm{m} / \mathrm{v})$. Após $24 \mathrm{~h}$ de incubação a $370^{\circ} \mathrm{C}$ e $160 \mathrm{rpm}$ em shaker, foi possível determinar a melhor produção em $0,19 \mathrm{U}$, nas condições de 20 g.L. ${ }^{1}$ de óleo de soja, 25 g.L. ${ }^{-1}$ de extrato de levedura e $40 \% \mathrm{~m} / \mathrm{v}$ do extrato de farelo de soja. Através do DCCR foi possível determinar a região de tendência para a obtenção da otimização da produção de lipase para a cepa selecionada, considerando uma região de confiança de $95 \%$ e $\mathrm{R}^{2}=0,8$.

Palavras-chave: lipase, planejamento experimental, microrganismo
\end{abstract}

Lipases are enzymes of great commercial interest as they can be used on many different areas of chemical industry, with emphasis in clothing, food and detergent industries. Lipases also can be used to make the industrial production cleaner, acting on biodiesel production and even used on fatty wastewater treatment. Although the enzyme has many routes where it can be obtained, the microbial one is the most used in industry. Realizing the industrial significance of lipases utilization, the present work had as its goal the isolation and selection of lipase producer microorganisms, as well the enzyme production by submerged fermentation optimization. It was isolated 12 different strains, 3 strains of which showing a promising lipase production qualitative analysis. One of these strains was selected to be used in a series of assays based in a Central Composite Rotatable Design (CCRD) $2^{3}$ intending to optimize the strain's enzymatic activity. The variables analyzed on the CCRD was soybean oil and yeast extract concentrations and the $\mathrm{m} / \mathrm{v}$ percentage of an soybean bran extract. After $24 \mathrm{~h}$ of incubation under $37^{\circ} \mathrm{C}$ and $160 \mathrm{rpm}$ in a shaker, it was found the best enzymatic production in $0,19 \mathrm{U}$, under the conditions of $20 \mathrm{~g} . \mathrm{L}^{-1}$ of soybean oil, $25 \mathrm{~g} . \mathrm{L}^{-1}$ of yeast extract and $40 \% \mathrm{~m} / \mathrm{v}$ of soybean bran extract. Using the CCRD, it was possible to determinate the region to obtain the lipase production optimization to the selected strain, considering a confidence region of $95 \%$ and $\mathrm{R}^{2}=0,8$.

Keywords: lipase, experimental design, microrganism

\section{INTRODUÇÃO}

Enzimas são catalisadores bastante eficientes, pois podem ser utilizadas em um número maior de processos do que os catalisadores convencionais. Além disso, a utilização de enzimas como biocatalisadores leva a uma redução do tempo e do número de etapas das reações que elas aceleram [1]. Outra vantagem é de que as enzimas são muito específicas e geralmente atuam sob condições mais moderadas que a maioria dos catalisadores químicos. Estudos demonstram que a engenharia enzimática também é uma técnica promissora quanto à busca de uma produção industrial mais limpa, pois as enzimas são altamente biodegradáveis e reduzem a quantidade de rejeitos gerados nos processos que catalisam [2]. 
Dentre as enzimas que mais se destacam, estão as lipases que catalisam reações de hidrólise em triglicerídeos convertendo-os em ácidos graxos e glicerol. Por outro lado, elas também atuam em reações de esterificação, interesterificação, alcoólise, acidólise e aminólise [3,4]. A versatilidade catalítica faz das lipases um dos grupos de enzimas mais utilizadas comercialmente, sendo considerado o terceiro maior grupo de enzimas em volume mundial de vendas e com uma participação no mercado mundial que cresce de maneira significativa [5, 6].

Devido à quantidade de reações catalisadas por lipases, elas podem ser aplicadas em diversas áreas, tais como na indústria oleoquímica, na indústria têxtil e na indústria de detergentes, sendo que nesta última a utilização de lipases representa $32 \%$ da venda mundial de enzimas. Nas indústrias de fármacos e química fina, por conta da regio e enantiosseletividades, as lipases também encontram ampla aplicação, bem como nas indústrias de couros onde as lipases são aplicadas para a remoção de gorduras e pelos. Duas áreas relativamente novas e extremamente promissoras da aplicação das lipases são o tratamento de efluentes gordurosos e a produção de biodiesel, que vêm ganhando espaço nos últimos anos dentre os estudos de aplicação da enzima [6, 7, 8]. As amplas possibilidades de aplicações das lipases reforçam sua importância econômica para vários setores produtivos.

Lipases são encontradas em fontes animais, vegetais e microbianas, sendo esta a via mais utilizada em escala industrial. A enzima obtida dessa fonte possui menores custos de produção agregados, facilidade de reprodução do processo em escala industrial e uma variedade interessante de características físico-químicas. Todas essas características das lipases microbianas e o número extenso de microrganismos produtores potenciais tornam o isolamento de cepas selvagens, bem como da enzima produzida por elas, estrategicamente interessante para a aplicação em diferentes processos industriais $[8,9]$.

A otimização de parâmetros experimentais é uma etapa crítica em um trabalho científico ou tecnológico, devendo ser realizada no início da pesquisa. Usualmente, a otimização é realizada por meio da análise de uma variável por vez, um método dispendioso e que demanda muito tempo de avaliação. Portanto, os sistemas de planejamento fatorial se destacam ao permitir a avaliação simultânea do efeito de um grande número de variáveis, economizando tempo e dinheiro na otimização de um processo [10].

No presente trabalho foi realizado o isolamento de microrganismos e sua seleção quanto à produção de lipases. Também foi efetuada a otimização da produção da enzima via fermentação submersa através de um Delineamento Composto Central Rotacional (DCCR) baseado em análises estatísticas.

\section{MATERIAL E MÉTODOS}

\subsection{Isolamento e seleção}

\subsubsection{Coleta de amostras}

As amostras foram coletadas em pontos que apresentavam maior quantidade de deposição de gordura, tais como caixa de gordura e chapa usada para preparar carnes. Com a ajuda de swabs esterilizados, as amostras foram extraídas e incubadas em caldo nutriente por $24 \mathrm{~h} \mathrm{a} 30^{\circ} \mathrm{C}$ em estufa bacteriológica.

\subsubsection{Isolamento}

Após a etapa anterior, uma alçada do meio contendo os microrganismos coletados foi utilizada para realizar a semeadura por esgotamento em placas de Petri contendo os meios Ágar Nutriente (NA) para o isolamento de bactérias. O mesmo procedimento foi realizado com placas de Petri contendo Potato Dextrose Agar (PDA) para o isolamento de fungos. As placas de NA foram incubadas em estufa bacteriológica a $30^{\circ} \mathrm{C}$ por $24 \mathrm{~h}$ e as placas de PDA foram incubadas nas mesmas condições por 7 dias. Posteriormente, foi realizada uma análise macroscópica, identificando as colônias e micélios que nelas se desenvolveram, utilizando textura e coloração aparentes como 
parâmetros de diferenciação. Depois de concluído o isolamento, as cepas foram levadas para análise em microscópio óptico para determinação das características morfológicas.

\subsubsection{Seleção de microrganismos produtores de lipase}

A seleção dos isolados quanto à capacidade de produção de enzimas lipases foi realizada de acordo com a metodologia proposta por Dingle et al. (2011) [11] com modificações. As cepas isoladas foram semeadas em placas contendo 18 g.L. $\mathrm{L}^{-1}$ de ágar, $10 \mathrm{~g} . \mathrm{L}^{-1}$ de azeite de oliva, $1 \mathrm{~g} . \mathrm{L}^{-1}$ de tween 80 e $2 \%$ de rodamina B. As placas foram incubadas em estufa a $30^{\circ} \mathrm{C}$ por $48 \mathrm{~h}$ e posteriormente analisadas em um transiluminador UV, onde a produção de lipase é evidenciada pela formação de halo fluorescente ao redor do ponto onde o microrganismo foi inoculado. A formação e medida do halo foram utilizadas como critério qualitativo para a seleção das cepas com potencial produção de lipase.

\subsection{Otimização da produção de lipase via fermentação submersa}

\subsubsection{Fermentação submersa}

A fermentação submersa foi realizada com base na metodologia descrita por Colla et al. (2015) [12], com algumas modificações. O meio utilizado conteve uma extração de farelo de soja obtida pela fervura de farelo de soja em água a $100^{\circ} \mathrm{C}$, extrato de levedura como fonte de nitrogênio e óleo de soja como indutor nas concentrações definidas para o Delineamento. Além disso, foi utilizada de uma solução salina $10 \%$ (v/v) de composição 2 g.L. de $^{-1} \mathrm{KH}_{2} \mathrm{PO}_{4}, 1$ g.L $\mathrm{L}^{-1}$ de $\mathrm{MgSO}_{4}$ e $10 \mathrm{~mL} . \mathrm{L}^{-1}$ de uma solução de metais traços com 0,63 mg...-1 de $\mathrm{FeSO}_{4} \cdot 7 \mathrm{H}_{2} \mathrm{O}, 0,01 \mathrm{mg} \cdot \mathrm{L}^{-1}$ de $\mathrm{MnSO}_{4}$ e 0,62 $\mathrm{mg} . \mathrm{L}^{-1}$ de $\mathrm{ZnSO}_{4}$. Depois, $45 \mathrm{~mL}$ do meio de produção foram adicionados em erlenmeyers de 125

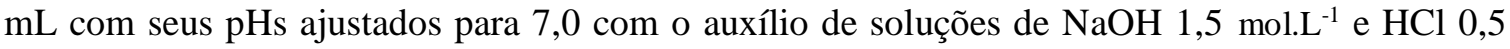
mol. $\mathrm{L}^{-1}$. Ao final, $5 \mathrm{~mL}$ do inóculo contendo o microrganismo selecionado foram adicionados ao meio de produção. $\mathrm{O}$ frasco foi incubado em shaker a $160 \mathrm{rpm} \mathrm{e} 37^{\circ} \mathrm{C}$ por $24 \mathrm{~h}$.

\subsubsection{Planejamento experimental}

No presente trabalho foi realizado um Delineamento Composto Central Rotacional (DCCR) $2^{3}$ com 3 repetições nos pontos centrais, totalizando 17 ensaios diferentes. As análises estatísticas dos ensaios foram realizadas no software STATISTIC 10.0. No Delineamento foi estudado o efeito de três variáveis na fermentação, sendo a concentração de óleo de soja $\left(\mathrm{g} . \mathrm{L}^{-1}\right)$, a concentração de extrato de levedura (g.L $\left.\mathrm{L}^{-1}\right)$ e a porcentagem da extração de farelo de soja $(\mathrm{m} / \mathrm{v})$. A Tabela 1 mostra a matriz experimental criada para o DCCR $2^{3}$ realizado pelo programa, onde as variáveis anteriormente citadas são X1, X2 e X3, respectivamente. O ponto 0 é o ponto central e os outros pontos na Tabela 1 são os pontos axiais. Para cada ensaio as medidas de atividade foram realizadas em triplicata e a média entre as repetições foi utilizada como resposta do Delineamento. Com base na matriz e no trabalho realizado por Colla et al. (2015) [12] foram definidos os valores reais para as variáveis estudadas, sendo apresentados na Tabela 2.

\subsubsection{Extração enzimática e testes de atividade}

Decorridas as 24 h estabelecidas para a fermentação, os erlenmeyers foram retirados do shaker e os meios de produção foram centrifugados a $4200 \mathrm{rpm}$ por $30 \mathrm{~min}$ e o sobrenadante, compreendendo o extrato enzimático, foi recolhido e utilizado nos testes posteriores. A atividade lipolítica foi determinada utilizando a metodologia proposta por Winkler e Stukmann (1979) [13] com modificações. O método consiste em medir o p-nitrofenol (p-NP) obtido a partir da hidrólise do p-nitrofenil palmitato (p-NPP). A solução de análise foi composta por $1 \mathrm{~mL}$ de uma solução de p-NPP, isopropanol na proporção de $3 \mathrm{mg} \cdot \mathrm{mL}^{-1}$ e $10 \mathrm{~mL}$ de outra solução contendo $3 \mathrm{~g}$ de Tween 80 dissolvidos em $450 \mathrm{~mL}$ de tampão fosfato $\mathrm{pH}$ 8,0. Depois, a solução final de análise foi mantida em equilíbrio térmico a $37^{\circ} \mathrm{C}$ e a $2,7 \mathrm{~mL}$ dela foi adicionado $0,3 \mathrm{~mL}$ do extrato enzimático. As amostras foram analisadas em espectrofotômetro a $410 \mathrm{~nm}$ durante $1 \mathrm{~min}$, tempo de processamento 
da reação de hidrólise do p-NPP, e as leituras de absorbância foram monitoradas a cada $5 \mathrm{~s}$. Para a determinação da concentração de p-NP após a reação, foi utilizada a Equação 1, sendo considerada uma unidade de atividade lipolítica (U) como a liberação de $1 \mu$ mol de p-NP por minuto de reação.

$$
\mathrm{C}=\mathrm{A} / \xi \cdot \mathrm{b}
$$

Onde: $\mathrm{C}=$ Concentração Molar de p-NP; $\mathrm{A}=$ Absorbância à 410nm; $\xi=$ Coeficiente de Extinção Molar do p-NP (18,5 mL/mol.cm); b= Caminho Óptico $(1 \mathrm{~cm})$

Tabela 1: Matriz experimental com as variáveis analisadas em cada ensaio realizado.

\begin{tabular}{cccc}
\hline & \multicolumn{3}{c}{ Variáveis analisadas da matriz experimental } \\
\cline { 2 - 4 } Ensaios & $\begin{array}{c}\text { Concentração de óleo de } \\
\text { Soja }\left(\mathbf{g} . \mathbf{L}^{-\mathbf{1}}\right)\end{array}$ & $\begin{array}{c}\text { Concentração de Extrato de } \\
\text { Levedura }\left(\mathbf{g . L ^ { - 1 }}\right)\end{array}$ & $\begin{array}{c}\text { Extração de } \\
\text { Soja }(\%) \\
\mathbf{X 3}\end{array}$ \\
\hline $\mathbf{X}$ & -1 & -1 & -1 \\
$\mathbf{2}$ & +1 & -1 & -1 \\
$\mathbf{3}$ & -1 & +1 & -1 \\
$\mathbf{4}$ & +1 & +1 & -1 \\
$\mathbf{5}$ & -1 & -1 & +1 \\
$\mathbf{6}$ & +1 & -1 & +1 \\
$\mathbf{7}$ & -1 & +1 & +1 \\
$\mathbf{8}$ & +1 & +1 & +1 \\
$\mathbf{9}$ & $-1,68$ & 0 & 0 \\
$\mathbf{1 0}$ & 1,68 & 0 & 0 \\
$\mathbf{1 1}$ & 0 & $-1,68$ & 0 \\
$\mathbf{1 2}$ & 0 & 1,68 & 0 \\
$\mathbf{1 3}$ & 0 & 0 & $-1,68$ \\
$\mathbf{1 4}$ & 0 & 0 & 1,68 \\
$\mathbf{1 5}$ & 0 & 0 & 0 \\
$\mathbf{1 6}$ & 0 & 0 & 0 \\
$\mathbf{1 7}$ & 0 & 0 & 0 \\
\hline
\end{tabular}

Tabela 2: Valores das variáveis para todos os pontos centrais e axiais.

\begin{tabular}{cccccc}
\hline & \multicolumn{5}{c}{ Valores atribuídos } \\
\cline { 2 - 6 } Variáveis analisadas & $\mathbf{- 1 , 6 8}$ & $\mathbf{- 1}$ & $\mathbf{0}$ & $\mathbf{+ 1}$ & $\mathbf{+ 1 , 6 8}$ \\
\hline Concentração de óleo $\left(\mathbf{g . L} \mathbf{L}^{-\mathbf{1}}\right)$ & 3,2 & 10,0 & 20,0 & 30,0 & 36,8 \\
Concentração de Extrato de Levedura $\left(\mathbf{g}^{-\mathbf{L}^{-1}}\right)$ & 0,0 & 10,0 & 25,0 & 40,0 & 50,2 \\
Extração de Soja $(\boldsymbol{\%})$ & 0,0 & 8,1 & 20,0 & 28,1 & 40,0 \\
\hline
\end{tabular}

\section{RESULTADOS E DISCUSSÃO}

\subsection{Isolamento e identificação}

Foram isoladas 12 cepas bacterianas diferentes, sendo 5 delas provenientes da chapa utilizada para preparar as carnes grelhadas e 7 originadas da caixa de gordura. Nenhum fungo foi isolado. As características das cepas isoladas foram determinadas e os resultados estão dispostos na Tabela 3. 
Tabela 3: Local de isolamento, características macroscópicas e identificação microscópica para cada cepa bacteriana isolada.

\begin{tabular}{cccc}
\hline & \multicolumn{3}{c}{ Características das cepas } \\
\cline { 2 - 4 } Cepas & $\begin{array}{c}\text { Local de } \\
\text { isolamento }\end{array}$ & Características Macroscópicas & $\begin{array}{c}\text { Tipo da } \\
\text { bactéria }\end{array}$ \\
\hline $\mathbf{1}$ & Chapa & Colônia com borda definida. Branca transparente. & Diplococos \\
$\mathbf{2}$ & Chapa & Branca Textura cremosa. & Bacilos \\
$\mathbf{3}$ & Chapa & Branca. Cremosa. Borda definida. & Cocos \\
$\mathbf{4}$ & Chapa & Branca. Cremosa. Borda definida & Cocos \\
$\mathbf{5}$ & Chapa & Branca. Aspecto gelatinoso. & Bacilos \\
$\mathbf{6}$ & Caixa de gordura & Amarela. Cremosa. Sem borda definida & Bacilos \\
$\mathbf{7}$ & Caixa de gordura & Amarela. Cremosa. Sem borda definida & Bacilos \\
$\mathbf{8}$ & Caixa de gordura & Borda definida. Branca. Cremosa. & Bacilos \\
$\mathbf{9}$ & Caixa de gordura & Transparente. Seca. Borda definida. & Bacilos \\
$\mathbf{1 0}$ & Caixa de gordura & Transparente. Seca. Borda definida. & Bacilos \\
$\mathbf{1 1}$ & Caixa de gordura & Amarelada. Cremosa. Borda indefinida. & Bacilos \\
$\mathbf{1 2}$ & Caixa de gordura & Amarelada. Cremosa. Borda indefinida & Cocos \\
\hline
\end{tabular}

\subsection{Ensaios qualitativos para a produção de lipase}

A maioria das cepas apresentou um halo de degradação fluorescente ao ser submetido à luz UV, confirmando que fontes com maior deposição de gordura são propícias para o isolamento de microrganismos lipolíticos tal como descrito na literatura. O trabalho de Roveda et al. (2010) [9], por exemplo, demonstrou que do isolamento de 21 cepas fúngicas a partir de efluentes de laticínios, 9 delas demonstraram capacidade lipolítica.

Dentre todas as cepas testadas, aquelas denominadas como 3, 4 e 11 apresentaram resultados muito melhores que as demais, com o halo de degradação se estendendo por todo o meio de cultura, demonstrando que foi obtida uma produção muito maior do que as outras cepas durante o mesmo tempo de incubação. Para fins ilustrativos, a Figura 1 compara as três cepas citadas, onde o halo obtido pela cepa 2 não foi tão expressivo (Figura 1a). Posteriormente, as três cepas foram submetidas à fermentação submersa para outro teste qualitativo. Dentre elas, a cepa 4 foi selecionada por apresentar os melhores resultados preliminares. A cepa foi utilizada no planejamento experimental.

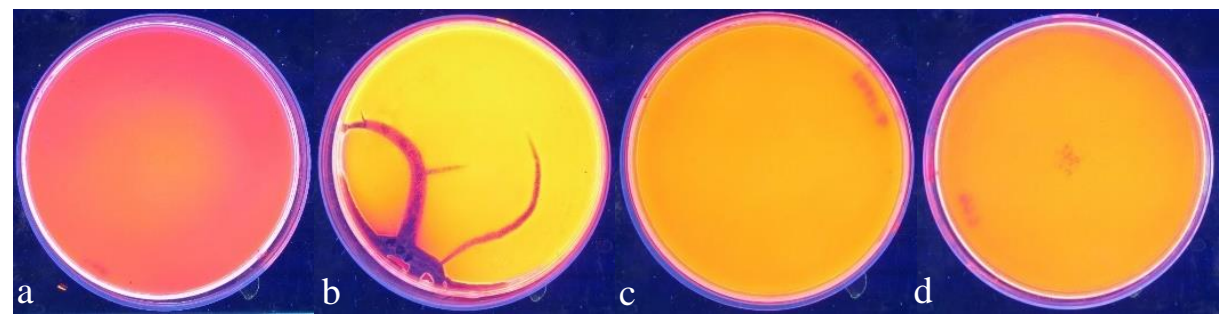

Figura 1: Imagens de algumas das cepas obtidas com o transiluminador UV onde: (a) cepa 2, (b) cepa 3, (c) cepa 4 e (d) cepa 11. A cor amarela fluorescente indica o halo de degradação. 


\subsection{Quantificação da atividade enzimática e planejamento experimental}

A Tabela 4 apresenta as atividades enzimáticas mensuradas pelo método da hidrólise de p-NPP para cada um dos ensaios estabelecidos no DCCR $2^{3}$.

Tabela 4: Respostas dos ensaios realizados para o DCCR $2^{3}$ em 24 h de incubação em termos de atividade enzimática medida.

\begin{tabular}{cc}
\hline Média das triplicatas de cada ensaio e desvio padrão \\
\hline Ensaios & Atividade enzimática (U) \\
\hline $\mathbf{1}$ & $0,018 \pm 0,003$ \\
$\mathbf{3}$ & $0,021 \pm 0,003$ \\
$\mathbf{4}$ & $0,100 \pm 0,030$ \\
$\mathbf{5}$ & $0,060 \pm 0,020$ \\
$\mathbf{6}$ & $0,100 \pm 0,030$ \\
$\mathbf{7}$ & $0,100 \pm 0,010$ \\
$\mathbf{8}$ & $0,120 \pm 0,010$ \\
$\mathbf{9}$ & $0,130 \pm 0,010$ \\
$\mathbf{1 0}$ & $0,050 \pm 0,010$ \\
$\mathbf{1 1}$ & $0,043 \pm 0,002$ \\
$\mathbf{1 2}$ & $0,025 \pm 0,003$ \\
$\mathbf{1 3}$ & $0,053 \pm 0,004$ \\
$\mathbf{1 4}$ & $0,045 \pm 0,006$ \\
$\mathbf{1 5}$ & $0,190 \pm 0,090$ \\
$\mathbf{1 6}$ & $0,084 \pm 0,006$ \\
$\mathbf{1 7}$ & $0,023 \pm 0,002$ \\
\hline
\end{tabular}

Na Tabela 5 são apresentadas as respostas dos Coeficientes de Regressão para as interações de cada variável, onde L significa a interação linear e Q a interação quadrática. Com 95\% de confiança, apenas a interação linear da concentração $\left(\mathrm{g} . \mathrm{L}^{-1}\right)$ de extrato de levedura e linear e quadrática da porcentagem do extrato de farelo de soja foram estatisticamente significativas, afetando positivamente a atividade enzimática. Entretanto, não foram encontradas interações estatisticamente significativas entre as variáveis independentes nos intervalos estudados. Da mesma maneira, a Figura 2 demonstra as variáveis estatisticamente significativas para a atividade enzimática ( $\mathrm{p}$-valor $<0,05$ ), indicando também que o aumento da concentração da variável possui influência positiva na resposta.

Tabela 5: Tabela com os efeitos das variáveis estudadas no DCCR $2^{3}$, considerando a resposta da atividade enzimática em 24 h de fermentação.

\begin{tabular}{ccccc}
\hline Fatores & Coeficientes de Regressão & p-valor & Limite Inferior & Limite Superior \\
\hline Média & 0,04769209 & 0,008859 & 0,016278 & 0,079106 \\
X1 (L) & $-0,0037475055$ & 0,566988 & $-0,018500$ & 0,011005 \\
X1 (Q) & 0,00212184013 & 0,766313 & $-0,014115$ & 0,018359 \\
X2 (L) & 0,0160860466 & 0,036558 & 0,001334 & 0,030839 \\
X2 (Q) & $-0,0010123629$ & 0,886949 & $-0,017250$ & 0,015225 \\
X3 (L) & 0,0360993576 & 0,000673 & 0,021347 & 0,050852 \\
X3 (Q) & 0,0271572424 & 0,005497 & 0,010920 & 0,043394 \\
X1X2 & $-0,00484459459$ & 0,570995 & $-0,024120$ & 0,014430 \\
X2X3 & 0,00447972973 & 0,599704 & $-0,014795$ & 0,023755 \\
X1X3 & $-0,00811486486$ & 0,352644 & $-0,027390$ & 0,011160 \\
\hline
\end{tabular}




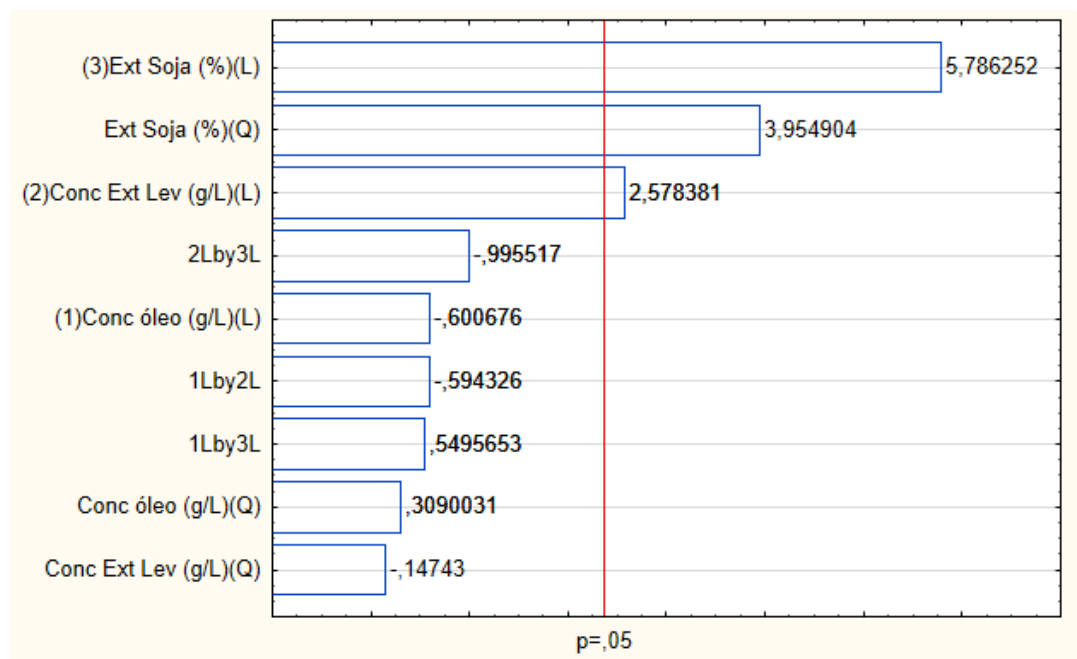

Figura 2: Gráfico de Pareto com a análise da influência das variáveis estatisticamente significativas na resposta da atividade enzimática

Com base na Tabela 4 foi possível também estabelecer a Equação 2, que mede a atividade lipolítica em função das variáveis predeterminadas na faixa experimental analisada.

$$
\mathrm{Y}=0,047692+0,016086 \cdot \mathrm{X} 2+0,036099 \cdot \mathrm{X} 3+0,027157 \cdot \mathrm{X} 3^{2}
$$

Onde: $\mathrm{Y}=$ atividade enzimática da lipase; $\mathrm{X} 2$ = concentração de extrato de levedura; $\mathrm{X} 3=$ porcentagem $\mathrm{em} \mathrm{m} / \mathrm{v}$ de farelo de soja

A Tabela 6 apresenta a análise de variância (ANOVA) para os ensaios realizados, indicando um $\mathrm{R}^{2}=0,8$, satisfatório para experimentos biotecnológicos.

Tabela 6: Tabela ANOVA para os fatores analisados no DCCR $2^{3}$.

\begin{tabular}{cccccc}
\hline $\begin{array}{c}\text { Fonte de } \\
\text { variação }\end{array}$ & $\begin{array}{c}\text { Soma de } \\
\text { quadrados }\end{array}$ & $\begin{array}{c}\text { Graus de } \\
\text { liberdade }\end{array}$ & $\begin{array}{c}\text { Quadrado } \\
\text { médio }\end{array}$ & $\mathbf{F}_{\text {calc }}$ & P - valor \\
\hline Regressão & 0,031913 & 03 & 0,01063767 & & \\
Resíduos & 0,003721 & 13 & 0,00028623 & 37,164763 & 0,008859 \\
Total & 0,035634 & 16 & 0,00222712 & & \\
\hline
\end{tabular}

A partir da Tabela 6, foi possível realizar um teste para comparação de duas variâncias (Teste F). O F tabelado foi igual a 3,41 e o F calculado, exposto na Tabela 5, foi igual a 37,164763. Como $\mathrm{F}$ calculado > F tabelado, isso indica que o modelo encontrado a partir do DCCR $2^{3}$ (Equação 2) é estatisticamente representativo do processo analisado.

Através do software STATISTIC 10.0 também foi possível plotar a superfície de resposta da atividade enzimática em função das duas variáveis estatisticamente significativas, a qual é apresentada na Figura 3. Os dados da Figura 3 permitem observar a tendência da máxima atividade lipolítica (regiões em vermelho) em seguir o aumento das concentrações dos níveis das variáveis consideradas estatisticamente significativas, mais evidentemente da extração do farelo de soja. 

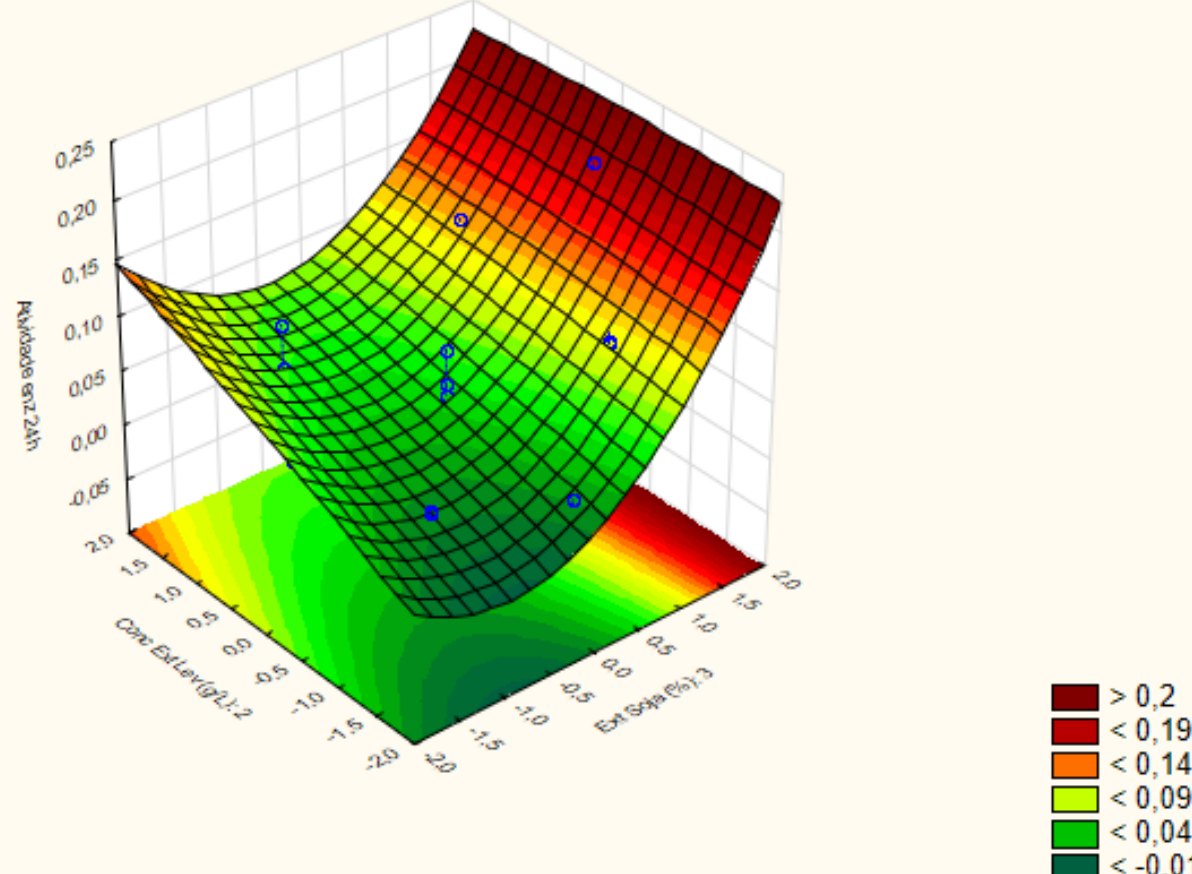

Figura 3: Superfície-resposta obtida no planejamento fatorial completo $2^{3}$ considerando os efeitos da concentração de extrato de levedura e da porcentagem do extrato de farelo de soja nas medidas de atividade enzimática.

Analisando os dados obtidos ao longo do DCCR $2^{3}$, é possível observar que o ensaio 14 (Tabela 4) apresentou o melhor valor de produção enzimática, considerando as condições de 20 g.L. ${ }^{-1}$ de óleo de soja e 25 g.L. ${ }^{-1}$ de extrato de levedura (pontos centrais do experimento) e $40 \% \mathrm{~m} / \mathrm{v}$ da extração de farelo de soja na composição do meio de produção. Cabe salientar que o óleo de soja não é o único indutor utilizado em fermentações submersas. Falony et al. (2006) [3], por exemplo, encontraram o azeite de oliva como melhor opção como indutor no processo da produção enzimática.

O ensaio 14 correspondeu a uma atividade enzimática de 0,19 U (Tabela 4), uma atividade média se comparada aos máximos obtidos por outros autores. Falony et al. (2006) [3], por exemplo, encontraram seus máximos de produção em 0,53 e 0,99 U.mL $\mathrm{mL}^{-1}$, utilizando o fungo Aspergillus niger. Da mesma forma, Roveda et al. (2010) [9] obtiveram seus máximos em 1,250, 2,042 e 2,250 U utilizando fungos dos gêneros Aspergillus e Penicillium. Entretanto, o extrato enzimático utilizado no presente trabalho foi analisado sem nenhum tipo de purificação além da centrifugação, e é possível afirmar que muito provavelmente a enzima obterá um resultado muito melhor se for purificada.

\section{CONCLUSÃO}

A coleta dos microrganismos foi bem-sucedida, pois a partir das fontes coletadas foram isoladas 12 cepas bacterianas.

O método de determinação qualitativa da produção de lipase também foi eficiente, apontando a maioria das cepas analisadas como produtoras da enzima e as cepas 3, 4 e 11 como as melhores produtoras. Além disso, testes qualitativos a partir da fermentação em estado sólido demonstraram que a cepa 4 se enquadrou melhor na proposta do trabalho.

As análises de atividade enzimática pelo método da determinação espectrofotométrica do p-NP se mostraram rápidas e eficientes, adequando-se bem ao grande volume de amostras analisadas.

A partir das análises e do Delineamento Fatorial realizados, foi possível determinar que, para 24 $\mathrm{h}$ de fermentação, 20 g.L $\mathrm{L}^{-1}$ de óleo de soja, 25 g.L $\mathrm{L}^{-1}$ de extrato de levedura e $40 \%$ de extrato de farelo de soja são os melhores valores destas variáveis para se utilizar no meio de produção de lipase a partir do microrganismo isolado. 
Por fim, o Delineamento Fatorial foi eficiente ao determinar uma faixa de tendência para a melhor produção enzimática com boa confiança estatística. É possível afirmar que, depois de passar por métodos de purificação, as enzimas lipases produzidas nesse trabalho podem ser testadas em experimentos que visem diversificar suas formas de uso e agregar valor aos produtos obtidos.

\section{AGRADECIMENTOS}

Os autores agradecem à FAPITEC/SE pela concessão da bolsa de iniciação científica fornecida para a realização deste trabalho através do Programa Institucional de Bolsas de Iniciação Científica (PIBIC) da Universidade Federal de Sergipe.

\section{REFERÊNCIAS BIBLIOGRÁFICAS}

1. Choi J, Han S, Kim H. Industrial applications of enzyme biocatalysis : Current status and future aspects. Biotechnol Adv. 2015 Nov;33(7):1443-54, doi:10.1016/j.biotechadv.2015.02.014

2. Raman K, Henning P. Environmental assessment of enzyme use in industrial production -a literature review. J Clean Prod. 2013 Mar;42:228-40, doi:10.1016/j.jclepro.2012.11.005

3. Falony G, Armas JC, Mendoza JCD, Hernández JLM. Production of extracellular lipase from Aspergillus niger by solid-state fermentation. Food Technol Biotechnol. 2006 Apr/Jun;44(2):235-40.

4. Fleuri LF, Novelli PK, Delgado CHO, Pivetta MR, Pereira MS, Arcuri M de LC. Biochemical characterisation and application of lipases produced by Aspergillus sp. on solid-state fermentation using three substrates. Int J Food Sci Technol. 2014 Dec;49(12):2585-91, doi:10.1111/ijfs.12589

5. Hasan F, Shah AA, Hameed A. Industrial applications of microbial lipases. Enzyme Microb Technol. 2006 Apr;39(2):235-51, doi:10.1016/j.enzmictec.2005.10.016

6. Freire DMG, Castilho LR. Enzimas em Biotecnologia: Produção, Aplicações e Mercado. Rio de Janeiro: Editora Interciência; c2008. Chapter 16, Lipases em Biocatálise; p. 369-85.

7. Menoncin S, Domingues NM, Maria D, Freire DMG, Oliveira JV, Luccio M Di, Treichel H, Oliveira de D. Imobilização de lipases produzidas por fermentação em estado sólido utilizando Penicillium verrucosum em suportes hidrofóbicos. Ciênc. Tecnol. Aliment. 2009 Apr-Jun;29(2):4403,doi:10.1590/S0101-20612009000200033.

8. Sharma R, Chisti Y, Chand U. Production, purification, characterization, and applications of lipases. Biotechnol Adv. 2001 Dec;19(8):627-62, doi:10.1016/S0734-9750(01)00086-6

9. Roveda M, Hemkemeier M, Colla LM. Avaliação da produção de lipases por diferentes cepas de microrganismos isolados em efluentes de laticínios por fermentação submersa. Ciênc Tecnol Aliment. $2010 \mathrm{Jan} / \mathrm{Mar} ; 30(1): 126-31$, doi:10.1590/S0101-20612010000100019

10. Cunico MWM, Cunico, MM, Miguel OG, Zawadzki SF, Peralta-Zamora P; Volpato N. Planejamento fatorial: uma ferramenta estatística valiosapara a definição de parâmetros experimentaisempregados na pesquisa científica. Visão Acadêmica. 2008 Jun;9(1):23-32, doi:10.5380/acd.v9i1.14635

11. Dingle J, Reid WW, Solomons GL. The enzymatic degradation of pectin and other polysaccharides.II. Application of the "cup-plate" assay to the estimation of enzymes. J Sci Food Agr. 2006 Mar;4(3):14955, doi: $10.1002 /$ jsfa. 2740040305

12. Colla LM, Ficanha AMM, Rizzardi J, Bertolin TE, Reinehr CO, Costa JAV. Production and characterization of lipases by two new isolates of Aspergillus through solid-state and submerged fermentation. Biomed Res Int. 2015;2015:1-9, doi:10.1155/2015/725959

13. Winkler UK, Stuckmann M. Glycogen, Hyaluronate, and some other polysaccharides greatly enhance the formation of exolipase by Serratia marcescens. J. Bacteriol. 1979 Jun;138(3):663-670. 